
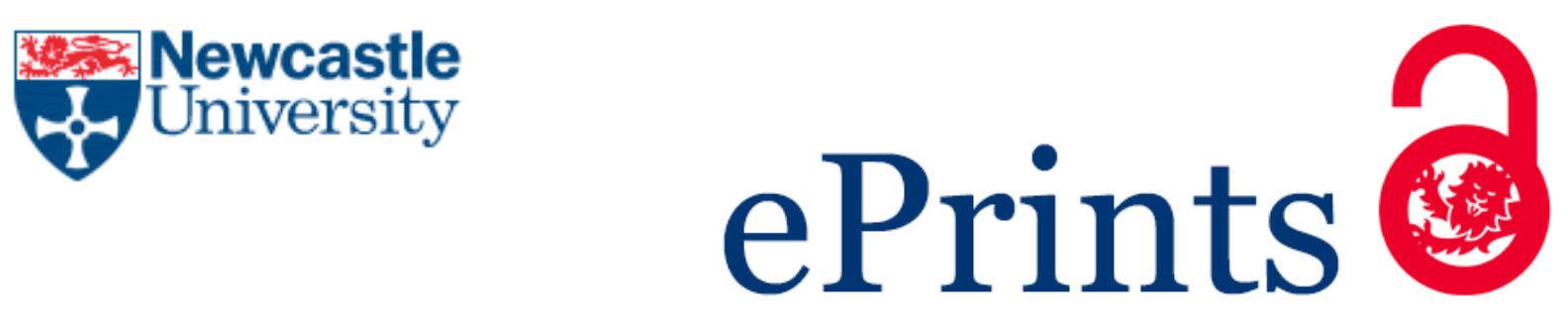

Panzone L, Lemke F, Petersen HL.

Biases in consumers' assessment of environmental damage in food chains

and how investments in reputation can help.

Technological Forecasting and Social Change (2016)

DOI: 10.1016/j.techfore.2016.04.008

\title{
Copyright:
}

(C) 2016. This manuscript version is made available under the CC-BY-NC-ND 4.0 license

DOI link to article:

http://dx.doi.org/10.1016/i.techfore.2016.04.008

Date deposited:

$14 / 04 / 2016$

Embargo release date:

19 October 2017

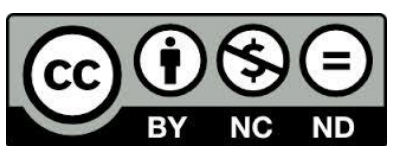

This work is licensed under a

Creative Commons Attribution-NonCommercial-NoDerivatives 4.0 International licence 


\section{BIASES IN CONSUMERS' ASSESSMENT OF ENVIRONMENTAL DAMAGE IN FOOD CHAINS AND HOW INVESTMENTS IN REPUTATION CAN HELP}

Luca Panzone*, Fred Lemke**, Henry L. Petersen***

* School of Agriculture, Food and Rural Development, Newcastle University, Agriculture building, King's Road, Newcastle-upon-Tyne, NE1 7RU, UK. E-mail: luca.panzone@,newcastle.ac.uk

** Services Marketing Research Group, Newcastle University Business School, Newcastle University, 5 Barrack Road, Newcastle-upon-Tyne, NE1 4SE, UK. E-mail: fred.lemke@newcastle.ac.uk

*** Department of Management, University of Wisconsin - La Crosse, 1725 State Street, La Crosse, WI 54601, USA.Email: hpetersen@uwlax.edu 
Sustainability is becoming increasingly relevant to consumers in their food choices. However, they may have a limited understanding of the environmental impact of their purchasing decisions and resort to perceptions and heuristics to guide them. In this study, consumers were asked to complete a categorisation task to determine whether they considered a product to have a high or low carbon footprint, with no information besides that contained on the product's front label. The results demonstrated that raw materials (food category), transportation (UK product), and manufacturing (level of processing) influenced the probability that an item would be classified as either having a low or high carbon footprint. These findings are embedded into the supply chain to explore the role of reputation in reducing the categorisation biases observed in the categorisation task.

Keywords: Sustainable Consumption; Consumer behaviour; Categorisation task; Reputation. 


\section{Introduction}

Carbon emissions are an increasing concern in many modern economies (e.g., Otto et al., 2015, Paroussos et al., 2015), and environmental regulation is currently paying attention to the role of consumers as agents of change (Boardman, 2008, Perino et al., 2014, Peters, 2010). Changes in consumer behaviour are estimated to have the potential to reduce US carbon emissions by as much as $41 \%$, often with little or no reduction in well-being (Dietz et al., 2009, Bin and Dowlatabadi, 2005). As a result, a growing number of policies targeting changes in consumption emphasize the need to present consumers with information on the environmental impact associated with the production of goods (Boardman, 2008, Clift and Wright, 2000). Carbon labels have attempted to provide consumers with a summary of the environmental information in the form of total carbon emissions, with some questionable results (e.g., Upham et al., 2011). Part of this failure might be driven by a number of factors such as the limited familiarity of consumers with carbon labels, the inability to understanding and differentiate between sustainable (i.e., low-carbon footprint) or unsustainable (i.e., highcarbon footprint) products, and how consumers use the information (see also Beattie, 2012).

This research explores the inferential process consumers use in assessing whether a food product has a high or low carbon footprint. Previous research suggests that consumers have a limited understanding of carbon footprint labelling (Bleda and Valente, 2009, Upham et al., 2011, Beattie, 2012). Additionally, sustainability information provided in the media has been shown to be often unrelated to expenditures in sustainable food categories (Bellotti and Panzone, 2016), suggesting that this type of information might not be very effective in driving behaviour. Nevertheless, in the absence of accurate information on the environmental impact caused by the production and consumption of products, consumers have been shown to rely upon external cues, which are likely to be imprecise and based upon specific (possibly biased) expectations and (possibly faulty) assumptions (e.g., Beattie, 2012, Gifford, 2011, 
Gifford, 2014, Whitmarsh et al., 2011). An inaccurate inference could lead environmentallyconscious consumers to systematically purchase high-carbon footprint food items whilst believing them to be low-carbon.

When assessing the environmental impact of a product, consumers are also challenged with understanding the supply chain and determining which particular stage is responsible for the environmental damage (Clift and Wright, 2000, Maloni and Brown, 2006). By summarizing the environmental impact into one measure, the carbon footprint can mask the contribution of each individual constituent. For instance, farming accounts for a large quota of the carbon footprint of meat production (Nijdam et al., 2012), but this information is not identifiable from the value of the carbon footprint, and consumers might consider other agents in the chain to be the cause of the problem. Similarly, the production process can influence the perceived sustainability of health programs and foods (Vermeer et al., 2013, Verbeke et al., 2007).

Consumers can infer the impact of a food choice by using heuristics that establish a probabilistic relation between different stages of the production process and their respective environmental damage, using a mental process similar to covariational thinking (Spellman, 1997). This process would predict that consumers infer whether a good has a low or high carbon footprint by determining the carbon intensity of each stage involved in its supply chain. For example, they may believe that an imported product is high in carbon because transport leads to environmental damage. This heuristic mirrors the 'food miles' paradigm (Weber and Matthews, 2008a, Kemp et al., 2010), in which 'distance' is used as a proxy measure of a product's emissions. Similarly, consumers may perceive that a high carbon footprint is caused by technological intensity, contextualised in terms of the amount of processing required (Monteiro, 2009) and the degree to which technology contributes to the final identity of the product (Palda, 1986). Finally, consumers might attribute the cause of a 
high carbon footprint to the inherent nature of a product: consumers classify products as either 'vices', which give immediate reward but cause long-term social problems, or 'virtues', which entail delayed gratification but give long-term social benefits (Van Doorn and Verhoef, 2011, Gorissen and Weijters, 2016); consumers might then assume that 'vice' products, for instance foods considered unhealthy, have high carbon footprint.

This article discusses the findings of a sustainability categorisation exercise, where a number of consumers were asked to classify a list of foods as 'high carbon' or 'low carbon'. In particular, the article builds upon the current but limited research around food products and environmental quality (Pivato et al., 2008, Bleda and Valente, 2009, Siegrist et al., 2015, Visschers and Siegrist, 2015). In the empirical exercise, the research explores three stages of the food supply chain: the production of raw ingredients versus industrial manufacturing (the level of processing, see Monteiro, 2009), transport (origin, refer to Kemp et al., 2010), as well as the nature of the good (for instance, agriculture or animal farming; see, e.g.,Van Doorn and Verhoef, 2011). This exercise allows a comparison between the true carbon footprint of a product and a consumer's perception of the carbon footprint. By presenting a mixture of products that differ in their supply chain, in terms of food category, manufacturing, and origin, it is possible to estimate how each of these three constituents of a supply chain influence the probability of an item being classified as having a high or low carbon footprint. Results indicate that consumers use information on the supply chain in the categorisation task, and while they show no bias in the carbon assessment of manufacturing, there are biases associated to different food categories (with the exception of meat products) and their origin.

This article is organised as follows. The next section discusses the concept of carbon footprint in a food supply chain context. Section 3 is dedicated to consumer behaviour, and explores the potential for biases that influence the perceptions of food products with respect to sustainability. Section 4 documents the finding of the empirical categorisation task, 
demonstrating that a consumer's perception of sustainability may be influenced by a number of variables. Section 5 presents a model explaining the implications of these results in a supply chain setting, proposing potential corrective measures that could protect members of a supply chain from the negative consequences of the biases. Section 6 discusses the implications of this research, followed by the conclusion in section 7 .

\section{The Carbon Footprint of Foods}

The environmental sustainability of a product may be estimated using any one of three main measures (Galli et al., 2012): the carbon footprint, which measures the amount of greenhouse gases emitted by a product during its life cycle; the ecological footprint, which measures the demand for renewable resource production (e.g., land) associated to consumption; and the water footprint, which measures the volume of water needed to produce, supply, and consume a product. The concept of the carbon footprint has become a prominent candidate for use as a summary indicator of the environmental damage of a food product to be put on labels (Pandey et al., 2011, Vanclay et al., 2011, Perino et al., 2014, Boardman, 2008). Carbon footprints are measured by observing the amount of greenhouse gas emissions associated to the life of a good along its supply chain, from the production of its raw ingredients, up to its consumption and the disposal of waste (Pandey et al., 2011, Garnett, 2011, Sundarakani et al., 2010) using a Life Cycle Assessment (LCA) approach (Weidema et al., 2008, Currás-Pérez et al., 2009, Lemke and Luzio, 2014). The growing use of LCA increased the availability of carbon footprint data, which aligns with global warming research (e.g., Keeling, 2008) by measuring environmental quality in carbon dioxide equivalents $\left(\mathrm{CO}_{2} \mathrm{e}\right)$.

The amount of carbon emitted in the atmosphere can vary enormously across different food products, reflecting the heterogeneity that characterises their supply chain (Garnett, 
2011, Maloni and Brown, 2006). According to Smedman et al. (2010) there are four main aspects of the supply chain that contribute to the carbon footprint of food: a production phase, which captures the emissions related to the production of raw materials (e.g., crops), including agricultural inputs such as fertilisers; a manufacturing phase, which refers to the emissions from the actual production of the product (e.g., energy, chemicals, and other industrial inputs); a packaging phase, which deals with the emissions associated with packaging; and a transportation phase, which refers to the transportation of ingredients and foods from one stage to another (farms to firms, manufacturers to retailers, and retailers to consumers). Because most products offered by UK retailers are packaged, and only certain food categories can be found loose (e.g., fruit and vegetables), the impact of packaging is difficult to identify statistically. Therefore, the remainder of the article will focus on the emissions generated from production, manufacturing, and transportation.

An important element that differentiates the environmental impact of food products is the level of processing required during the manufacturing process (Espinoza-Orias et al., 2011). Monteiro (2009) classified food products into three levels. First, minimally processed foods are products that use a minimal amount of technology (e.g., washing, juicing, fermenting, or packaging) that does not substantially change their raw form. Fresh fruit and vegetables, meat, and milk belong to this category. Second, processed food ingredients require a level of technology that significantly alters the nature of the original raw product, leading to foods that are used as intermediates to other processed foods. Examples are flours, oils, and sugars. Third, highly processed foods apply specific technologies (e.g., baking, frying, curing, and smoking) to minimally processed foods and highly processed ingredients to obtain complex foods. Snacks, biscuits, soft drinks, processed meats, and ready meals are 
representative examples ${ }^{1}$. Differences in the carbon footprint of processed foods stem from production and processing, which are major contributors of greenhouse gases (Wakeland et al., 2012, pp. 225-226). This is partly due to the additional energy needed for processing (Rizet et al., 2012) as well as the refrigeration of the ingredients and/or the final product (Schmidt Rivera et al., 2014). Notably, food preparation and consumption (Espinoza-Orias et al., 2011, Dietz et al., 2009, Weber and Matthews, 2008b) and waste (Scholz et al., 2015) also play a relevant role in the final footprint of foods, but are not captured in this exercise.

Another factor that can account for the differences in the carbon footprint of similar products is the transportation of a product to its destination market (Espinoza-Orias et al., 2011). Products belonging to the same food category have similar production phases and supply chains, and often require comparable inputs and processes, making transportation the delineating factor of their carbon footprint. However, transportation has a rather small influence on the total carbon footprint of different food products (Weber and Matthews, 2008a), particularly on high-carbon footprint foods, e.g., meat (Webb et al., 2013). Lastly, there are significant differences in emissions associated with the overall nature of a product, which accounts for commonalities in supply chains. For instance, emissions from meat production are high (Nijdam et al., 2012, Williams et al., 2006), while vegetables and horticultural products have a low carbon footprint (Williams et al., 2006, Drewnowski et al., 2015, Stoessel et al., 2012). Likewise, certain categories (e.g., sweets, starchy foods, and soft drinks) tend to have a relatively low carbon footprint (Drewnowski et al., 2015, Andrews et al., 2011), even though they require industrial production. The large number of factors contributing to the carbon footprint of a good might explain the difficulties consumers

\footnotetext{
${ }^{1}$ The level of food processing somewhat correlates with the length of the supply chain: minimally processed products will typically only have agricultural producers supplying retailers; processed food ingredients will most likely have a small number of agricultural producers supplying a manufacturer that supplies retailers; while highly processed foods tend to have a much more complex structure with multiple producers and intermediaries supplying a manufacturer who then supplies retailers.
} 
experience in using these values in their choices (Upham et al., 2011, Bleda and Valente, 2009).

\section{Consumer Assessment of Environmental Damage in a Supply Chain}

Despite the need to provide information on the environmental impact of consumption, carbon footprints are not an easy concept for consumers. Research highlights that consumers struggle in understanding information on the environmental quality of goods (Bleda and Valente, 2009, Upham et al., 2011), and dedicate little time in reading this information during product evaluations (Beattie, 2012). In fact, unlike calorific content, which is familiar and on the pack of all products, the concept of a 'carbon footprint' is new to consumers (Boardman, 2008), and does not yet appear in the marketplace. This inability of consumers to perceive the correct environmental quality of goods can result in difficulties in translating attitudes into behaviour (Brunsø et al., 2004), and an unwillingness to pay for the premium price manufacturers require to make investments in environmental quality sustainable over time (e.g., Gagliardi et al., 2014). The failure to provide a measure of environmental damage on labels suggests consumers make choices by having to infer the environmental impact of the different options available to them.

Models of decision-making with uncertain quality (Broniarczyk and Alba, 1994) indicate that consumers infer a product's performance using observable characteristics (Broniarczyk and Alba, 1994) such as prices (Rao, 2005), the retailer's behaviour (Janakiraman et al., 2006), or other cues such as the behaviour of a supplier (Morales, 2005). The market offering, the actions of supply chain members, and marketing communication cover these aspects (Lemke and Petersen, 2013). Under conditions of perfect information and unlimited cognitive processing, these cues are generally expected to be sufficient for consumers to objectively identify quality. Similarly, if consumers held perfect information on 
the structure of the supply chain, as well as exact information on the environmental impact of each members operating in it, they could derive the correct environmental impact of the products they consume (Bleda and Valente, 2009). In reality, information on the structure of differing supply chains is generally not available to consumers, and these chains can be particularly complex in a globalized trading environment like the UK (e.g., Green and Foster, 2005, Maloni and Brown, 2006). When information is incomplete, consumers are then forced to rely upon their intuition and external cues. Nonetheless, there is limited research exploring how consumers assess the environmental quality of food products (Pivato et al., 2008, Bleda and Valente, 2009).

The horsemeat scandal presents an interesting case study on the problem of information flows in a complex supply chain. The delivery of mincemeat for ready-made products from an animal farmer to a manufacturer was mediated by at least two brokers and another industrial manufacturer. The final product then reached the end-consumer after the further intermediation of a retailer. The very long and complex supply chain made quality control and traceability of ingredients difficult and highlighted how deceiving the information on an ingredient list (mincemeat) could be to consumers (Premanandh, 2013, Elliot, 2014). However, revealing the complexity of food chains to consumers is considered problematic in the food industry, where transparency can cause the loss of a competitive advantage (Young and Hobbs, 2002).

To this extent, inferring the influence of a chain of events for a specific outcome is often explained by models of causal attribution (e.g., Kelley and Michela, 1980). The term 'outcome' here refers to either a concrete state (e.g., death in Mandel, 2003), or any expected final state (e.g., quality of a good in Weiner, 2000). There are two primary models that explain how consumers assign causality in a series of events. The first is counterfactual thinking (Tversky and Kahneman, 1974). Here, individuals imagine a counterfactual scenario 
in which each linkage in a chain of events is modified or removed. The event that eliminates the end outcome when removed is then identified as the primary cause. The second paradigm, covariational thinking, views individuals as establishing causality by assessing the correlation between each step of the chain of events and the outcome based on personal knowledge and experience (Spellman, 1997). In this case, the likely cause is the stage with the highest correlation with the outcome. For an example, by applying counterfactual thinking, consumers would estimate the carbon footprint by thinking what the value would be if a stage of the food chain is modified, e.g., by thinking what the impact of British beef would be if the same beef was not British. By applying covariational thinking, consumers would mentally assess the correlation between each stage of the food chain and the outcome, e.g., by determining the correlation between industrial processing and $\mathrm{CO}_{2}$ emissions to estimate the impact of potato chips. In practice, both types of thinking lead consumers to view some attributes as likely to have low-emissions (e.g., British, associated to low transport emissions), and others as having high-emissions (e.g., industrial processing).

The inferential process of estimating the environmental impact of a product by assessing the structure of a supply chain can then be seen as a consumer asking oneself what stage of the supply chain caused the product to be damaging the environment. However, this inference is not always accurate and may be subject to a number of biases: consumers often form heuristics, which can carry substantial error if the information used in the assessment is imprecise (Gigerenzer and Gaissmaier, 2011). For example, transportation is not a prominent component of carbon emissions (Weber and Matthews, 2008a), but food miles remain a key measure of environmental friendliness for consumers (Kemp et al., 2010), and imported food is generally viewed as unsustainable (Whitmarsh et al., 2011). Consumers also have imperfect views on the carbon footprint of different food categories: scientific research recognises meat and dairy as unsustainable (McMichael et al., 2007, Garnett, 2011), but not 
many consumers consider meat production and consumption as damaging the environment (Whitmarsh et al., 2011). Similarly, while agriculture emits a large share of greenhouse gases in the UK (Garnett, 2011), agricultural products are considered more sustainable than industrial ones (Van Doorn and Verhoef, 2011). Finally, consumers tend to agree that industrial production is unsustainable (Whitmarsh et al., 2011).

\section{Consumer Perception of Sustainability - An Empirical Exploration}

To assess consumers' perceptions of food sustainability, the empirical analysis explores how consumers classify various products on the basis of their expected carbon footprint. Modern markets in developed economies increasingly present consumers with products that bundle a variety of attributes, which help consumers pursue certain consumption goals (e.g., health, environmental friendliness, or saving money). While several manufacturers adopted carbon labels, consumers seem to be generally unaware of the environmental impact of their choices (Upham et al., 2011). The research presented here explores consumers' perception of environmental damage from the production of food. The exercise uses the carbon footprint as a measure of environmental damage caused, preferring it to water or ecological footprint primarily because of its increasing data availability, often at the level of a specific product (e.g., Berners-Lee, 2011). The statistical analysis compares perceived and actual damage.

\subsection{Sample and Methodology}

To explore consumer decision-making, an opportunity sample of 42 individuals (undergraduate and postgraduate students at a Northern UK university) were paid $£ 5$ to take part in a categorization exercise (as in Chernev and Gal, 2010, Lamberts, 1995). The sample included 16 men and 26 women, with an average age of 22.6 years (range: 18-47). Participants were presented with the images of 70 food products commonly available in 
supermarkets sourced from online shopping websites, covering a range of food types. Table 1 presents a classification of the 70 products into six food categories.

Insert Table 1 here

The carbon footprint of 67 of these products was available in CCalc ${ }^{2}$ (http://www.ccalc.org.uk/). In the classification task, each participant was taken to a room where they were presented with three category labels on the wall: 'Low carbon footprint', 'High carbon footprint', and 'Don't know'. They were then given a tray containing the seventy randomly assorted food products on printed cards, and asked to stick each product card onto the wall under the category they thought that particular item belonged. The classification of each respondent was anonymously noted on a recording sheet, along with age and gender. The small sample prevents a generalisation of the findings, but this allowed researchers to observe consumer decision-making for each respondent, using a withinindividual identification of effects.

\subsection{A Statistical Model of Categorisation}

In terms of modelling, the decision-making process can be represented by defining consumers $j$ classifying a good $i$ with characteristics $x_{i}$ as 'low carbon' or 'high carbon'. The perceived footprint of a product, $S_{i j}$, can then be expressed as a function of characteristics as

$$
S_{i j}=\alpha_{j}+\beta_{j} \cdot x_{i}+\varepsilon_{i j}
$$

\footnotetext{
${ }^{2}$ No reliable carbon footprint information could be obtained for Covent Garden Soup, lemon, and mango.
} 
The coefficient $\beta_{j}$ is a consumer-specific assessment, to capture individual beliefs unique to a respondent. The actual perceived sustainability of a product $S_{i j}^{*}$ is latent (Greene and Hensher, 2010), with the observed variable corresponding to

$$
\begin{array}{ccc}
S_{i j}=1 & \text { if } & -\infty<S_{i j}^{*} \leq \mu_{1} \\
S_{i j}=2 & \text { if } & \mu_{1}<S_{i j}^{*} \leq \mu_{2} \\
S_{i j}=3 & \text { if } & \mu_{2}<S_{i j}^{*}, \infty
\end{array}
$$

where $S_{i j}=1_{i j}$ if the item is classified as 'High carbon footprint' (low sustainability), $S_{i j}=2$ if the 'Don't know' option is selected, and $S_{i j}=3$ if the item is classified as 'Low carbon footprint' (high sustainability). The 'Don't know' option is represented as an intermediate outcome because it reflects the situation where the respondent assigns significant probability to both the item having low and high carbon footprint (Wang, 1997). The scale in equation (2) can be reversed to reflect the perceived carbon footprint of a product as

$$
\begin{array}{lll}
S_{i j}=1 & \text { if } & \text { 'Low carbon' } \\
S_{i j}=2 & \text { if } & \text { 'Don't know' } \\
S_{i j}=3 & \text { if } & \text { 'High carbon' }
\end{array}
$$

going from low to high carbon footprint. Equations (1) and (3) are estimated as an ordered probit, and the marginal probability of the consumer classifying a product in category $k=1$, 2, 3 for a set of dummy variables corresponds to

$$
\begin{aligned}
\frac{\partial P\left(S_{i j}=k\right)}{\partial x_{i}}= & {\left[\phi\left(\mu_{j-1}-\beta_{j} x_{i} \mid x_{i}=1\right)-\phi\left(\mu_{1}-\beta_{j} x_{i} \mid x_{i}=1\right)\right] \beta_{j} } \\
& -\left[\phi\left(\mu_{j-1}-\beta_{j} x_{i} \mid x_{i}=0\right)-\phi\left(\mu_{1}-\beta_{j} x_{i} \mid x_{i}=0\right)\right] \beta_{j}
\end{aligned}
$$

\subsection{Results}

Table 2 reports the average perceived sustainability (scores from 1 to 3 , as in equation (2)) for each category in column four. The average true carbon footprint is listed in column two. 
This value is used to derive an arbitrary classification, shown in column three, where 'low carbon footprint' classes are considered to have an average footprint below $1.5 \mathrm{~kg} \mathrm{CO}_{2} \mathrm{eq}$, while 'high carbon footprint' classes are above $2.5 \mathrm{~kg} \mathrm{CO}_{2}$ eq. The 'Don't know' option falls in-between the two intervals and covers the range from 1.5 to 2.5. Grey colour coding indicates the two sustainability classes as well as the class where consumers are unsure.

Insert Table 2 here

Figure 1 compares the true and perceived carbon footprint of the different classes of products. The figure shows that the discrepancy between the true and perceived value is largest for fruit and soft drinks, which tend to be viewed as less sustainable than they actually are. By contrast, meat and dairy, and fish and eggs, are considered more sustainable than they actually are. Participants appear to have a rather accurate perception of the sustainability of starchy foods. Figure 2 plots the average perceived carbon footprint of a product (calculated for the 42 participants) against its true carbon footprint. The figure shows that overall the perceived footprint of a product is positively related to its actual emission (i.e., larger footprint is high carbon, as expected); however, the graph indicates substantial heterogeneity in the classification of low carbon goods, which can be perceived as having either a relatively high carbon footprint or low carbon footprint. On the other hand, consumers tend to correctly classify very high carbon goods (British beef steak, New Zealand Lamb, and Organic beef mince). As a result, consumers manifest more inaccurate categorisations for low-carbon food products, while being more accurate in the classification of very high carbon options. 
To determine the impact of specific supply chain features on the perceived sustainability of each product, equation (1) has been estimated for each individual respondent separately. The individual marginal probability of a specific category being classed as 'low carbon footprint' (relative to vegetables) is obtained from equation (4). Figure 3 depicts the average impact of origin, level of processing, and food category on the probability of a product being classed as sustainable for the 42 participants, with confidence intervals obtained from 1,000 bootstrapping replications. The class 'Vegetables' was chosen as a reference dummy for product categories because this category was perceived as the most sustainable among the list of items in Table 1 (see also Van Doorn and Verhoef, 2011).

Figure $3 \mathrm{a}$ shows that all categories, apart from fruit, have a significantly lower probability of being considered sustainable. Importantly, sweets and drinks, which rely purely on industrial processing, have a significantly larger probability of being considered unsustainable than fruits and vegetables. Similarly, all products of animal origin are seen as unsustainable. On the other hand, products with clear links to agricultural production (fruit, vegetables, and starchy food - mostly beans and tubers) are systematically classed as relatively low carbon. In terms of the level of processing, Figure $3 \mathrm{~b}$ indicates that processed food ingredients tend to be seen as significantly less sustainable than minimally processed foods, while highly processed foods are not significantly different from the baseline category. Finally, Figure $3 \mathrm{c}$ shows that a British label significantly increases the perceived 
sustainability of a product. This result is consistent with expectations of low carbon associated to local food with a short supply chain.

Insert Figure 3 here

The same equation (1) is estimated by regressing the perceived carbon footprint of a product on the true carbon footprint of the good (see appendix for the values), repeating the same procedure as before, but using the scale in equation (3). The estimated marginal impact of the carbon footprint on the expected classification is reported in Figure 3d. Results indicate the presence of a significantly positive but low correlation between true and expected carbon footprint: on average, participants are able to correctly categorise products by their carbon footprint, and a unit increase in the true $\mathrm{kgCO}_{2}$ equivalent (per kilo or litre) leads to an increase in the probability of the good being classified as 'high carbon footprint' of 0.0076 . Figure 4 shows that the distribution of the marginal effect in the sample has a bimodal distribution. Moreover, a sample of consumers (18 respondents) reported a negative association between actual $\mathrm{CO}_{2}$ and the carbon content categorisation (mean: -0.0074, range: -0.0178 to -0.0004$)$, representing a substantial bias; a larger sample (24 respondents) presented the expected positive correlation (mean: 0.0271 , range: 0.0010 to 0.1147 ). 
As a robustness check, equation (1) is also estimated using a multi-level ordered probit. This approach effectively replicates the previous analysis, but presents some efficiency gains by estimating the individual and product-level equations simultaneously. Specifically, the regression refers to a random intercept model, where the intercept varies across respondents but the slopes have been kept constant across consumers to facilitate convergence of the likelihood function. In the regression, the error term is clustered at the individual level. The model is estimated also for the true carbon footprint, which is regressed against the scale in equation (3). In this second estimate, the model allows for both an intercept and a coefficient that are unique for each respondent ${ }^{3}$. Table 3 confirms the results above, highlighting that all products are perceived as significantly less sustainable than vegetables. Moreover, processed food ingredients are perceived as less sustainable than minimally processed foods, while highly processed foods are perceived as having a carbon footprint comparable to minimally processed foods. As expected, UK products are perceived as more sustainable than non-UK products. Finally, the multilevel regression confirms the significantly positive and low correlation between actual and estimated carbon footprint of the product.

Insert Table 3 here

Having access to actual carbon footprint data also allows a comparison between perception and actual emissions. To assess whether the consumer perception of carbon footprint aligns to the carbon content of food, the next step is to regress the carbon footprint of a product (in logarithmic form) over the characteristics of the product as

\footnotetext{
${ }^{3}$ The same regression has been estimated adding a quadratic term and using the logarithm of the actual carbon footprint, as in Attari et al. (2010). However, the coefficient of the quadratic term was not significant. As a result, the article only reports the estimates of a model with a simple linear term because of the ease of interpretation of the coefficient and its marginal effect.
} 


$$
\ln \left(C O_{2}\right)_{i}=\delta_{0}+\delta_{1} \cdot x_{i}+\varepsilon_{i}
$$

Estimated results are presented in Table 4. As observed earlier, processed food ingredients have a significantly higher carbon footprint than minimally processed food, while highly processed foods are not significantly different from the baseline. This result indicates that the assessment of the carbon footprint of the level of processing does not present a bias. On the other hand, UK and foreign products have the same carbon footprint, despite consumers perceiving local goods as more sustainable (Table 3), in line with the food miles paradigm (Kemp et al., 2010). Consumers imperfectly assess the environmental impact of food categories: meat has a significantly higher carbon footprint than vegetables, while fruit and drinks have significantly lower values. Hence, while consumers show no bias in the assessment of the carbon footprint associated to agriculture and manufacturing, they appear to have biases in the assessment of the environmental impact of food categories and the origin of the product.

\section{Insert Table 4 here}

\section{Reputation as a Tool for the Management of Perceptual Biases}

The empirical exercise presented above showed that consumers have a limited ability to discriminate between low and high carbon footprint food items. The decision-making observed in the empirical analysis may arise from the information consumers have available to make optimal (i.e., efficient rather than accurate) inferences. In particular, participants lacked the information regarding the environmental quality of the goods supplied in the market (e.g., specific knowledge of the production process and its carbon emissions) and 
were then required to draw upon their experiences and or personal information. In addition to information on labels, consumers can make assessments reflecting on the reputation of individual supply chain members or on the (positive or negative) environmental reputation of specific production stages. Subjective information may be inaccurate, and these inaccuracies could be effectively addressed through the reorientation of supply chain management.

Reputation in the supply chain context has generated a considerable degree of interest amongst researchers (e.g., Roehrich et al., 2014, Hoejmose et al., 2014, Czinkota et al., 2014, Lemke and Petersen, 2013, Petersen and Lemke, 2015). Its role on perceptual biases can be illustrated in a model of information flow developed by Lemke and Petersen (2013), which outlines the mechanisms in Figure 5. The model presents a stylised version of a supply chain, which does not account for several dimensions, e.g., geographical location or complex chains with multiple tiers. The point where market offerings and consumers meet can be found on the right hand side of the figure. The manufacturer is in the centre, while suppliers are to the far left. Consumers may not know the full structure of the supply chain: as consumers purchase a product from a retailer, there is a probability that they are unaware of a tier-2 raw material supplier (e.g., the farmer who supplied the meat), and their associated environmental activities $^{4}$. This limited information of the role of supply chain members creates a knowledge gap that forces the environmentally motivated consumer to make choices based upon imperfect information and limited knowledge.

Insert Figure 5 here

\footnotetext{
${ }^{4}$ Some manufacturers have hundreds of partners upstream contributing to a product, even prior to that product moving on to a retailer (Petersen and Lemke, 2015).
} 
In Figure 5, every supplier tier contributes their technological or organizational competence to the end-product (Maloni and Brown, 2006), and the technological complexity and intensity accumulates from left to right, moving towards the retailer-consumer interface. The accumulation of greenhouse gas emissions moves in the same direction, as indicated in the model. An attributed reputation may instead flow upstream, in the opposite direction of the downstream flow of the product offering (e.g., Foxconn's alleged mismanagement of employees and the resulting negative publicity for Apple; see, e.g., Chan et al., 2013). With regards to sustainability in the food supply chain, this means that a coffee retailer may have the reputation of offering high-quality products because he sells coffee manufactured by an organization based in a country with a strong reputation for coffee, e.g., Colombia. Similarly, if this coffee retailer also engages in recycling and community health, it will earn a positive reputation for both its high quality products as well as for sustainability (e.g., Lauritsen and Perks, 2015). Similarly, a Colombian coffee bean supplier may gain an international reputation for 'high quality' when supplying a global coffeehouse chain that targets the premium market segment.

As a result, reputation can inform consumers on the attempt of each agent in the supply chain to minimise the amount of emission contributed to the final carbon footprint value, potentially correcting the biased perceptions of the consumers. In this respect, one organization within a chain may establish itself as being responsible and thereby creating a positive environmental reputation that signals interest in sustainability to consumers. Petersen and Lemke (2015) call these firms Reputational Owners (ROs, in the figure). Reputational Borrowers (RBs) upstream or downstream in the supply chain may be then perceived as having a responsible reputation in the eyes of consumers by having an association with the RO. RBs may then benefit by reputational spillover, which can be positive or negative, so that a sustainable or unsustainable act committed by a single member of the chain can have 
repercussion on the whole chain. For instance, the tainted chicken scandal in the UK was caused by the failure of some farmers to engage in best production practices (Lawrence and Wasley, 2014), and this action damaged the reputation of other members of the supply chain, affecting particularly the retailers.

Partnering firms can play an active role in facilitating consumer decision-making, because their reputation can potentially guide and correct consumer perceptions of the environmental damage caused by a product. Included with information on the product or service offered, its production process, and communication, three dimensions of sustainability in food chains are particularly relevant to consumers (see Lemke and Petersen, 2013): 'product class image' (e.g., meat), as expectations on sustainability vary across different product categories (Van Doorn and Verhoef, 2011); 'country of origin image' (e.g., British), as the origin of a product can bias quality expectations (Bilkey and Nes, 1982); and CSR (e.g., organic production, or fair-trade commerce), as consumers value companies that support socially responsible activities (Becker-Olsen et al., 2006, Besley and Ghatak, 2007). Activities such as certifications, third-party validations, or other forms of environmental accreditation have been shown to influence consumer behaviour (Grunert et al., 2014), and can generate a spillover effect. The figure includes these activities in the 'communication' dimension - an up and downstream information flow that ties members together in the chain. However, research on the link between reputation and perceived environmental impact is still limited.

\section{Discussion}

Sustainability is playing an increasingly important role in modern markets, where policymakers and manufacturers are dedicating large amounts of resources to measure the environmental impact of products and to inform consumers on the long-term implications of 
their consumption. While the environmental consequences of current consumption patterns tend to be relevant to consumers (e.g., Van Doorn and Verhoef, 2011, Cornelissen et al., 2008), there is a limited understanding on whether consumers are able to estimate the impact of their choices, and how knowledge is translated into behaviour (e.g., Boardman, 2008, Beattie, 2012). In this study, participants were presented with a list of existing food products and had to determine their environmental quality, i.e., indicate whether they thought the product was low or high carbon footprint. Among the different measures of the environmental impact of consumer goods (Galli et al., 2012), the task employed here used the carbon footprint as a relevant metric because of its policy relevance (Boardman, 2008), the relatively high familiarity with the term among UK consumers (Whitmarsh et al., 2011), and the larger data availability at product level (Berners-Lee, 2011).

The study identified the tendency of participants to categorize products based upon expectations drawn from available information. Specifically, respondents expected local raw food products with limited processing (e.g., vegetables) to be more sustainable than more complex products (e.g., sweets), particularly if foreign and partly manufactured. This finding confirms previous research that consumers may have a limited understanding of sustainability when it comes to food products (Grunert et al., 2014). The results of this article also lend support to earlier qualitative findings (e.g., Bleda and Valente, 2009, Upham et al., 2011, Beattie, 2012) with respect to the use of carbon labels. In particular, the results support the need for more information on the environmental impact of different food products (Jaffry et al., 2004). With no information, consumers rely on external cues, and seem to misjudge the carbon content of food products. Part of the problem may be linked to conceptual difficulties in understanding the term 'carbon footprint' (Whitmarsh et al., 2011), or to being able of visualising an abstract concept (carbon footprint) in their daily life (Hartikainen et al., 2014, Jaffry et al., 2004). 
In the categorisation exercise, heuristics appear to stem from an assessment of the damage caused by the production process associate to the specific food product. Part of the decision-making may be the result of food category bias (whether it is perceived as a 'vice' or a 'virtue', see Van Doorn and Verhoef, 2011). This bias is possibly influenced by the perceived healthiness of the categories, given the significant correlation between kilocalories and carbon footprint (Drewnowski et al., 2015). A final bias relates to the 'food miles' paradigm (e.g., Kemp et al., 2010). The UK-study shows that being British increases the probability of a food being considered low carbon, despite showing no significant difference in actual carbon footprint. Given the focus of this exercise (related to supply chain characteristics), the study could not explore some stages of consumption (e.g., waste produced after consumption) that may similarly influence consumer expectations. The results also do not exactly explain the origin of the biases observed here, and future research could use qualitative methods to assess which element of the supply chain is considered responsible for the environmental impact of a good.

Part of the problem in categorising products correctly may stem from perceptions on the reputation of a supply chain. Specifically, consumers may consider some supply chains (e.g., meat) and some production steps within a chain (e.g., transport) inherently high in carbon footprint. Investments in environmental reputation leading to certified labels have been shown to influence behaviour (e.g., Grunert et al., 2014), suggesting that reputation could correct misperceptions by signalling to consumers a firm's interest on sustainability. At present, however, supply chain problems are mostly managed upstream (i.e., from consumers to manufacturers), and supply chain members often underestimate the impact of their offerings, communications, and actions on their own reputation and that of supply chain partners. Investments in reputation can reverse this orientation by dedicating more attention to the market, benefitting the whole supply chain. Retailers and manufacturers, as 
'reputational owners', are in an optimal position to invest in reputation, because proximity to consumers exposes them to the greatest risk of reputational damage (e.g., Roehrich et al., 2014, Hoejmose et al., 2014, Czinkota et al., 2014, Lemke and Petersen, 2013, Petersen and Lemke, 2015). Reputation can then be maintained by providing consumers with accurate and relevant information that they can easily access and understand, minimising undesired spill over effects of reputation caused by careless agents along the supply chain whilst helping consumers make better choices.

Future research should continue the line of inquiry presented in this paper to capture and interpret the subjective dimension of sustainability. Importantly, the study of carbon footprint labelling is relevant beyond its link to environmental sustainability: the label is still at the development stage, and research in this area can provide relevant insights to academics on how labels work in practice, while helping businesses and policymakers design effective labels that help consumers make better choices. To this extent, a limitation of the empirical exercise presented here is that consumers had the time to ponder as much as they wanted to determine the carbon content of the food items presented to them. The same exercise might differ enormously under time pressure (Suri and Monroe, 2003, Lamberts, 1995), which is an important factor for consumers shopping for food in large retailers (e.g., supermarkets; see, Jabs and Devine, 2006). Under time pressure, consumers would be expected to rely more heavily on heuristics and external cues (Suri and Monroe, 2003), leading to more acute differences between actual and expected carbon footprint than what is documented in this article. Future research could explore the impact of time pressure on categorisation.

From a methodological standpoint, exploratory research, such as in-depth interviewing (e.g., Kvale and Brinkmann, 2009), critical incidents technique (e.g., Flanagan, 1954), repertory grid technique (e.g., Kelly, 1963), laddering technique (e.g., Reynolds and Gutman, 1988), or a combination of these, can explore the decision-making processes of consumers to 
understand how consumers perceive sustainability in grocery shopping and their level of awareness of the concept (e.g., following Whitmarsh et al., 2011). Exploratory approaches can be particularly relevant to allow consumers to articulate the meaning of sustainability in the context of product choice and purchase. At the same time, quantitative research would allow the statistical modelling of perceptions, leading to improvements in the accuracy of statistical methods used to study psychological decision-making (Slovic, 2007). Quantitative research could then test for more specific hypotheses by using specific demand models (e.g., Deaton and Muellbauer, 1980) that generalise current research and can determine how knowledge, attitudes and perceptions translate into behaviour. Finally, the origin of the biases observed in this research could be determined using experimental research (e.g., Suri and Monroe, 2003), determining causal relations between misperceptions and potential causes.

\section{Conclusions}

This article explores consumer's perception of sustainability. Participants were presented with a series of food products, which they had to categorize as either low or high carbon emissions. Consistent with theories of heuristic decision-making, classifications followed the expected carbon impact of the level of processing, country of origin, and the product category. These assessments are in some cases biased. Investments in reputation within the supply chain could reduce the reliance on heuristics by removing the uncertainty over the environmental quality of a product. Reputation entails establishing a communication flow between supply chain partners (e.g., farmers and retailers), which can influence consumer perceptions, and possibly lead to a spill over effect. Sustainability of the food

supply chain involves the contribution of all individual members to the chain. As a result, joint proactive actions may prevent or limit the damage that one member of the chain could cause to others, protecting agents along the supply chain as well as consumers. 


\section{ACKNOWLEDGEMENTS}

The research presented in this article was funded by the Sustainable Consumption Institute, University of Manchester. We would like to thank Laura Sale for her role in the collection of the data, and Viviana Albani for comments on previous versions of this work.

\section{BIBLIOGRAPHY}

ANDREWS, J. C., BURTON, S. \& KEES, J. 2011. Is Simpler Always Better? Consumer Evaluations of Front-of-Package Nutrition Symbols. Journal of Public Policy \& Marketing, 30, 175-190.

BEATTIE, G. 2012. Psychological effectiveness of carbon labelling. Nature Clim. Change, 2, 214-217.

BECKER-OLSEN, K. L., CUDMORE, B. A. \& HILL, R. P. 2006. The impact of perceived corporate social responsibility on consumer behavior. Journal of Business Research, 59, 46-53.

BELLOTTI, E. \& PANZONE, L. 2016. Media effects on sustainable food consumption. How newspaper coverage relates to supermarket expenditures. International Journal of Consumer Studies, 40, 186-200.

BERNERS-LEE, M. 2011. How bad are bananas?: the carbon footprint of everything, Greystone Books.

BESLEY, T. \& GHATAK, M. 2007. Retailing public goods: The economics of corporate social responsibility. Journal of Public Economics, 91, 1645-1663.

BILKEY, W. J. \& NES, E. 1982. Country-of-origin effects on product evaluations. Journal of international business studies, 13, 89-100.

BIN, S. \& DOWLATABADI, H. 2005. Consumer lifestyle approach to US energy use and the related CO2 emissions. Energy Policy, 33, 197-208.

BLEDA, M. \& VALENTE, M. 2009. Graded eco-labels: A demand-oriented approach to reduce pollution. Technological Forecasting and Social Change, 76, 512-524.

BOARDMAN, B. 2008. Carbon labelling: too complex or will it transform our buying? Significance, 5, 168-171. 
BRONIARCZYK, S. M. \& ALBA, J. W. 1994. The Role of Consumers' Intuitions in Inference Making. Journal of Consumer Research, 21, 393-407.

BRUNSØ, K., SCHOLDERER, J. \& GRUNERT, K. G. 2004. Closing the gap between values and behavior-a means-end theory of lifestyle. Journal of Business Research, 57, 665-670.

CHAN, J., PUN, N. \& SELDEN, M. 2013. The politics of global production: Apple, Foxconn and China's new working class. New Technology, Work and Employment, 28, 100-115.

CHERNEV, A. \& GAL, D. 2010. Categorization Effects in Value Judgments: Averaging Bias in Evaluating Combinations of Vices and Virtues. Journal of Marketing Research, 47, 738-747.

CLIFT, R. \& WRIGHT, L. 2000. Relationships Between Environmental Impacts and Added Value Along the Supply Chain. Technological Forecasting and Social Change, 65, 281295.

CORNELISSEN, G., PANDELAERE, M., WARLOP, L. \& DEWITTE, S. 2008. Positive cueing: Promoting sustainable consumer behavior by cueing common environmental behaviors as environmental. International Journal of Research in Marketing, 25, 46-55.

CURRÁS-PÉREZ, R., BIGNÉ-ALCAÑIZ, E. \& ALVARADO-HERRERA, A. 2009. The Role of Self-Definitional Principles in Consumer Identification with a Socially Responsible Company. Journal of Business Ethics, 89, 547-564.

CZINKOTA, M., KAUFMANN, H. R. \& BASILE, G. 2014. The relationship between legitimacy, reputation, sustainability and branding for companies and their supply chains. Industrial Marketing Management, 43, 91-101.

DEATON, A. \& MUELLBAUER, J. 1980. An Almost Ideal Demand System. The American Economic Review, 70, 312-326.

DIETZ, T., GARDNER, G. T., GILligAN, J., STERN, P. C. \& VANDENBERGH, M. P. 2009. Household actions can provide a behavioral wedge to rapidly reduce US carbon emissions. Proceedings of the National Academy of Sciences, 106, 18452-18456.

DREWNOWSKI, A., REHM, C. D., MARTIN, A., VERGER, E. O., VOINNESSON, M. \& IMBERT, P. 2015. Energy and nutrient density of foods in relation to their carbon footprint. The American Journal of Clinical Nutrition, 101, 184-191.

ELLIOT, C. 2014. Elliott Review into the Integrity and Assurance of Food Supply Networks - Final Report. A National Food Crime Prevention Framework. HM Government.

ESPINOZA-ORIAS, N., STICHNOTHE, H. \& AZAPAGIC, A. 2011. The carbon footprint of bread. The International Journal of Life Cycle Assessment, 16, 351-365. 
FLANAGAN, J. C. 1954. The critical incident technique. Psychological Bulletin, 51, 327358.

GAGLiARDI, D., NIGLIA, F. \& BATTISTELLA, C. 2014. Evaluation and design of innovation policies in the agro-food sector: An application of multilevel self-regulating agents. Technological Forecasting and Social Change, 85, 40-57.

GALli, A., WIEDMANN, T., ERCIN, E., KNOBLAUCH, D., EWING, B. \& GILJUM, S. 2012. Integrating Ecological, Carbon and Water footprint into a "Footprint Family" of indicators: Definition and role in tracking human pressure on the planet. Ecological Indicators, 16, 100-112.

GARNETT, T. 2011. Where are the best opportunities for reducing greenhouse gas emissions in the food system (including the food chain)? Food Policy, 36, Supplement 1, S23-S32.

GIFFORD, R. 2011. The dragons of inaction: Psychological barriers that limit climate change mitigation and adaptation. American Psychologist, 66, 290-302.

GIFFORD, R. 2014. Environmental Psychology Matters. Annual Review of Psychology, 65, 541-579.

GIGERENZER, G. \& GAISSMAIER, W. 2011. Heuristic Decision Making. Annual Review of Psychology, 62, 451-482.

GORISSEN, K. \& WEIJTERS, B. 2016. The negative footprint illusion: Perceptual bias in sustainable food consumption. Journal of Environmental Psychology, 45, 50-65.

GREEN, K. \& FOSTER, C. 2005. Give peas a chance: Transformations in food consumption and production systems. Technological Forecasting and Social Change, 72, 663-679.

GREENE, W. H. \& HENSHER, D. A. 2010. Modeling ordered choices: a primer, Cambridge University Press.

GRUNERT, K. G., HIEKE, S. \& WILLS, J. 2014. Sustainability labels on food products: Consumer motivation, understanding and use. Food Policy, 44, 177-189.

HARTIKAINEN, H., ROININEN, T., KATAJAJUURI, J.-M. \& PULKKINEN, H. 2014. Finnish consumer perceptions of carbon footprints and carbon labelling of food products. Journal of Cleaner Production, 73, 285-293.

HOEJMOSE, S. U., ROEHRICH, J. K. \& GROSVOLD, J. 2014. Is doing more doing better? The relationship between responsible supply chain management and corporate reputation. Industrial Marketing Management, 43, 77-90.

JABS, J. \& DEVINE, C. M. 2006. Time scarcity and food choices: An overview. Appetite, 47, 196-204. 
JAFFRY, S., PICKERING, H., GHULAM, Y., WHITMARSH, D. \& WATTAGE, P. 2004. Consumer choices for quality and sustainability labelled seafood products in the UK. Food Policy, 29, 215-228.

JANAKIRAMAN, N., MEYER, R. J. \& MORALES, A. C. 2006. Spillover effects: How consumers respond to unexpected changes in price and quality. Journal of Consumer Research, 33, 361-369.

KEELING, R. F. 2008. Recording Earth's Vital Signs. Science, 319, 1771-1772.

KELLEY, H. H. \& MICHELA, J. L. 1980. Attribution theory and research. Annual review of psychology, 31, 457-501.

KELLY, G. A. 1963. A Theory of Personality: The Psychology of Personal Constructs, London, W. W. Norton \& Company.

KEMP, K., INSCH, A., HOLDSWORTH, D. K. \& KNIGHT, J. G. 2010. Food miles: Do UK consumers actually care? Food Policy, 35, 504-513.

KVALE, S. \& BRINKMANN, S. 2009. InterViews: Learning the Craft of Qualitative Research Interviewing, London, Sage.

LAMBERTS, K. 1995. Categorization under time pressure. Journal of Experimental Psychology: General, 124, 161-180.

LAURITSEN, B. D. \& PERKS, K. J. 2015. The influence of interactive, non-interactive, implicit and explicit CSR communication on young adults' perception of UK supermarkets' corporate brand image and reputation. Corporate Communications: An International Journal, 20, 178-195.

LAWRENCE, F. \& WASLEY, A. 2014. Chicken factories inspected by FSA as Tesco reveals surprise spot check [Online]. The Guardian. Available: http://www.theguardian.com/business/2014/jul/25/chicken-factories-inspected-fsa-tescoreveals-surprise-spot-check [Accessed 25.07.2014 2014].

LEMKE, F. \& LUZIO, J. P. P. 2014. Exploring Green Consumers' Mind-set towards Green Product Design and Life Cycle Assessment: The Case of Sceptical Brazilian and Portuguese Green Consumers. Journal of Industrial Ecology, 18, 619-630.

LEMKE, F. \& PETERSEN, H. L. 2013. Teaching Reputational Risk Management in the Supply Chain. Supply Chain Management: An International Journal, 18, 413-428.

MALONI, M. \& BROWN, M. 2006. Corporate Social Responsibility in the Supply Chain: An Application in the Food Industry. Journal of Business Ethics, 68, 35-52. 
MANDEL, D. R. 2003. Judgment dissociation theory: An analysis of differences in causal, counterfactual and covariational reasoning. Journal of Experimental Psychology: General, 132, 419.

MCMICHAEL, A. J., POWLES, J. W., BUTLER, C. D. \& UAUY, R. 2007. Food, livestock production, energy, climate change, and health. The Lancet, 370, 1253-1263.

MONTEIRO, C. A. 2009. Nutrition and health. The issue is not food, nor nutrients, so much as processing. Public Health Nutrition, 12, 729-731.

MORALES, A. C. 2005. Giving Firms an "E" for Effort: Consumer Responses to HighEffort Firms. Journal of Consumer Research, 31, 806-812.

NIJDAM, D., ROOD, T. \& WESTHOEK, H. 2012. The price of protein: Review of land use and carbon footprints from life cycle assessments of animal food products and their substitutes. Food Policy, 37, 760-770.

OTTO, S. A. C., GERNAAT, D. E. H. J., ISAAC, M., LUCAS, P. L., VAN SLUISVELD, M. A. E., VAN DEN BERG, M., VAN VLIET, J. \& VAN VUUREN, D. P. 2015. Impact of fragmented emission reduction regimes on the energy market and on $\mathrm{CO} 2$ emissions related to land use: A case study with China and the European Union as first movers. Technological Forecasting and Social Change, 90, Part A, 220-229.

PALDA, K. S. 1986. Technological intensity: Concept and measurement. Research Policy, 15, 187-198.

PANDEY, D., AGRAWAL, M. \& PANDEY, J. 2011. Carbon footprint: current methods of estimation. Environmental Monitoring and Assessment, 178, 135-160.

PAROUSSOS, L., FRAGKOS, P., CAPROS, P. \& FRAGKIADAKIS, K. 2015. Assessment of carbon leakage through the industry channel: The EU perspective. Technological Forecasting and Social Change, 90, Part A, 204-219.

PERINO, G., PANZONE, L. A. \& SWANSON, T. 2014. MOTIVATION CROWDING IN REAL CONSUMPTION DECISIONS: WHO IS MESSING WITH MY GROCERIES? Economic Inquiry, 52, 592-607.

PETERS, G. P. 2010. Carbon footprints and embodied carbon at multiple scales. Current Opinion in Environmental Sustainability, 2, 245-250.

PETERSEN, H. L. \& LEMKE, F. 2015. Mitigating reputational risks in supply chains. Supply Chain Management: An International Journal, 20, 495-510.

PIVATO, S., MISANI, N. \& TENCATI, A. 2008. The impact of corporate social responsibility on consumer trust: the case of organic food. Business Ethics: A European Review, 17, 3-12. 
PREMANANDH, J. 2013. Horse meat scandal - A wake-up call for regulatory authorities. Food Control, 34, 568-569.

RAO, A. R. 2005. The quality of price as a quality cue. Journal of marketing research, 401405.

REYNOLDS, T. J. \& GUTMAN, J. 1988. Laddering Theory, Method, Analysis, and Interpretation. Journal of Advertising Research, 28, 11-31.

RIZET, C., BROWNE, M., CORNELIS, E. \& LEONARDI, J. 2012. Assessing carbon footprint and energy efficiency in competing supply chains: Review - Case studies and benchmarking. Transportation Research Part D: Transport and Environment, 17, 293300.

ROEHRICH, J. K., GROSVOLD, J. \& HOEJMOSE, S. U. 2014. Reputational risks and sustainable supply chain management: Decision making under bounded rationality. International Journal of Operations \& Production Management, 34, 695-719.

SCHMIDT RIVERA, X. C., ESPINOZA ORIAS, N. \& AZAPAGIC, A. 2014. Life cycle environmental impacts of convenience food: Comparison of ready and home-made meals. Journal of Cleaner Production, 73, 294-309.

SCHOLZ, K., ERIKSSON, M. \& STRID, I. 2015. Carbon footprint of supermarket food waste. Resources, Conservation and Recycling, 94, 56-65.

SIEGRIST, M., VISSCHERS, V. H. M. \& HARTMANN, C. 2015. Factors influencing changes in sustainability perception of various food behaviors: Results of a longitudinal study. Food Quality and Preference, 46, 33-39.

SLOVIC, P. 2007. If I look at the mass I will never act”: Psychic numbing and genocide. Judgment and decision making, 2, 79-95.

SMEDMAN, A., LINDMARK-MÅNSSON, H., DREWNOWSKI, A. \& EDMAN, A.-K. M. 2010. Nutrient density of beverages in relation to climate impact. Food \& Nutrition Research, 54, 10.3402/fnr.v54i0.5170.

SPELlMAN, B. A. 1997. Crediting Causality. Journal of Experimental Psychology, 126, 323-348.

STOESSEL, F., JURASKE, R., PFISTER, S. \& HELLWEG, S. 2012. Life Cycle Inventory and Carbon and Water FoodPrint of Fruits and Vegetables: Application to a Swiss Retailer. Environmental Science \& Technology, 46, 3253-3262.

SUNDARAKANI, B., DE SOUZA, R., GOH, M., WAGNER, S. M. \& MANIKANDAN, S. 2010. Modeling carbon footprints across the supply chain. International Journal of Production Economics, 128, 43-50. 
SURI, R. \& MONROE, K. B. 2003. The Effects of Time Constraints on Consumers' Judgments of Prices and Products. Journal of Consumer Research, 30, 92-104.

TVERSKY, A. \& KAHNEMAN, D. 1974. Judgment under Uncertainty: Heuristics and Biases. Science, 185, 1124-1131.

UPHAM, P., DENDLER, L. \& BLEDA, M. 2011. Carbon labelling of grocery products: public perceptions and potential emissions reductions. Journal of Cleaner Production, 19, 348-355.

VAN DOORN, J. \& VERHOEF, P. C. 2011. Willingness to pay for organic products: Differences between virtue and vice foods. International Journal of Research in Marketing, 28, 167-180.

VANCLAY, J., SHORTISS, J., AULSEBROOK, S., GILlESPIE, A., HOWELL, B., JOHANNI, R., MAHER, M., MITCHELL, K., STEWART, M. \& YATES, J. 2011. Customer Response to Carbon Labelling of Groceries. Journal of Consumer Policy, 34, 153-160.

VERBEKE, W., VANHONACKER, F., SIOEN, I., VAN CAMP, J. \& DE HENAUW, S. 2007. Perceived Importance of Sustainability and Ethics Related to Fish: A Consumer Behavior Perspective. AMBIO: A Journal of the Human Environment, 36, 580-585.

VERMEER, A. J. M., VAN ASSEMA, P., HESDAHL, B., HARTING, J. \& DE VRIES, N. K. 2013. Factors influencing perceived sustainability of Dutch community health programs. Health Promotion International.

VISSCHERS, V. H. M. \& SIEGRIST, M. 2015. Does better for the environment mean less tasty? Offering more climate-friendly meals is good for the environment and customer satisfaction. Appetite, 95, 475-483.

WAKELAND, W., CHOLETTE, S. \& VENKAT, K. 2012. Food transportation issues and reducing carbon footprint. In: BOYE, J. I. \& ARCAND, Y. (eds.) Green Technologies in Food Production and Processing. Boston, MA: Springer.

WANG, H. 1997. Treatment of "don't-know" responses in contingent valuation surveys: a random valuation model. Journal of Environmental Economics and Management, 32, 219-232.

WEBB, J., WILliAMS, A. G., HOPE, E., EVANS, D. \& MOORHOUSE, E. 2013. Do foods imported into the UK have a greater environmental impact than the same foods produced within the UK? The International Journal of Life Cycle Assessment, 18, 1325-1343. 
WEBER, C. L. \& MATTHEWS, H. S. 2008a. Food-Miles and the Relative Climate Impacts of Food Choices in the United States. Environmental Science \& Technology, 42, 35083513.

WEBER, C. L. \& MATTHEWS, H. S. 2008b. Quantifying the global and distributional aspects of American household carbon footprint. Ecological Economics, 66, 379-391.

WEIDEMA, B. P., THRANE, M., CHRISTENSEN, P., SCHMIDT, J. \& LØKKE, S. 2008. Carbon Footprint. Journal of Industrial Ecology, 12, 3-6.

WEINER, B. 2000. Attributional thoughts about consumer behavior. Journal of Consumer Research, 27, 382-387.

WHITMARSH, L., SEYFANG, G. \& O’NEILL, S. 2011. Public engagement with carbon and climate change: To what extent is the public 'carbon capable'? Global Environmental Change, 21, 56-65.

WILLIAMS, A., AUDSLEY, E. \& SANDARS, D. 2006. Determining the environmental burdens and resource use in the production of agricultural and horticultural commodities: Defra project report IS0205. Available at http://randd. defra. gov. uk/Default. aspx.

YOUNG, L. M. \& HOBBS, J. E. 2002. Vertical linkages in agri-food supply chains: changing roles for producers, commodity groups, and government policy. Review of Agricultural Economics, 24, 428-441. 


\section{TABLES}

\section{Table 1: Products presented in the classification task}

\begin{tabular}{|c|c|c|c|c|c|c|}
\hline Starchy food & Animal products & Vegetables & Fruit & Soft drinks & Sweets & Fish and Eggs \\
\hline Beans $^{(\mathrm{mpf})}$ & British Beef Steak $^{(\mathrm{mpf})}$ & Asparagus $^{(\mathrm{mpf})}$ & Apples $^{(\mathbf{m p f})}$ & Coca Cola $^{\text {(hpf) }}$ & Ben \& Jerry's ${ }^{(h p f)}$ & Alaskan Salmon $^{(\mathrm{mpf})}$ \\
\hline Cashews $^{(\mathrm{mpf})}$ & Chicken Breast Fillets $^{(\mathrm{mpf})}$ & Carrots $^{(\mathrm{mpf})}$ & Blueberries $^{(m p f)}$ & Evian $^{(\mathbf{m p f})}$ & $\operatorname{Cocoa}^{(\mathbf{p f i})}$ & Caged Eggs ${ }^{(m p f)}$ \\
\hline Dorset Cereal $^{(\mathrm{hpf})}$ & Cottage Pie ${ }^{(h p f)}$ & Chopped Tomatoes $^{(\mathbf{p f i})}$ & Fair-Trade Bananas ${ }^{(m p f)}$ & Fair-Trade coffee ${ }^{(\mathbf{p f i})}$ & Green\&Blacks Chocolate ${ }^{(\mathbf{h p f})}$ & Cod Fillets $^{(\mathrm{mpf})}$ \\
\hline Hovis White ${ }^{(\mathrm{hpf})}$ & Mild Cheddar ${ }^{(\mathbf{h p f})}$ & Crispy Salad ${ }^{(\mathbf{m p f})}$ & Fair-Trade Oranges ${ }^{(\mathbf{m p f})}$ & Innocent $^{(\mathrm{mpf})}$ & Honey $^{(\text {hpf })}$ & Mackerel (smoked) ${ }^{\text {(hpf) }}$ \\
\hline Kingsmill Wholemeal $^{(\mathrm{hpf})}$ & Mozzarella $^{(\text {hpf) }}$ & Lettuce $^{(\mathrm{mpf})}$ & Frozen Raspberries ${ }^{(\mathbf{p f i})}$ & Nescafe $^{(\mathbf{p f i})}$ & Kitkat $^{(h p f)}$ & Organic Eggs ${ }^{(\mathrm{mpf})}$ \\
\hline McCain potatoes ${ }^{(\mathrm{hpf})}$ & New Zealand Lamb ${ }^{(m p f)}$ & Mushrooms $^{(\mathrm{mpf})}$ & Organic Blueberries $^{(\mathbf{m p f})}$ & One $e^{(\mathbf{m p f})}$ & Mr Kipling ${ }^{(\mathbf{h p f})}$ & Tuna (canned) ${ }^{(\mathbf{h p f})}$ \\
\hline Pasta $^{\text {(hpf) }}$ & Organic Beef Mince ${ }^{(\mathbf{p f i})}$ & Olive Oil ${ }^{(\mathbf{p f i})}$ & Pineapple ${ }^{(m p f)}$ & PG tips tea ${ }^{(\mathbf{p f i})}$ & Sugar ${ }^{(\mathbf{p f i})}$ & \\
\hline Pitta bread ${ }^{(\text {hpf) }}$ & Organic Chicken $^{(\mathrm{mpf})}$ & Parsnips ${ }^{(m p f)}$ & Raisins $^{(\mathbf{p f i})}$ & Tropicana $^{(\mathbf{m p f})}$ & & \\
\hline $\operatorname{Pizza}^{(\mathrm{hpf})}$ & Turkey Breast Slice ${ }^{(\mathbf{m p f})}$ & Peas ${ }^{(m p f)}$ & Strawberries ${ }^{(\mathbf{m p f})}$ & & & \\
\hline Quaker Oats ${ }^{(\mathrm{hpf})}$ & Turkey Drummers ${ }^{(\mathbf{m p f})}$ & Tomatoes ${ }^{(\mathrm{mpf})}$ & & & & \\
\hline Soya ${ }^{(m p f)}$ & Waitrose Milk $^{(\mathrm{mpf})}$ & Covent Garden soup ${ }^{(\mathbf{h p f})}$ & & & & \\
\hline Tofu $^{(\text {hpf })}$ & Yeo Valley Milk ${ }^{(m p f)}$ & Lemon $^{(m p f)}$ & & & & \\
\hline Tyrrells Crisps $^{(\mathrm{hpf})}$ & Yeo Valley Yoghurt & Mango $^{(m p f)}$ & & & & \\
\hline Walkers Crisps ${ }^{(\mathrm{hpf})}$ & & & & & & \\
\hline
\end{tabular}

Note: $\mathrm{mpf}=$ minimally processed food; $\mathrm{pfi}=$ processed food ingredient; $\mathrm{hpf}=$ highly processed food. 
Table 2: Classification task and average category characteristics

\begin{tabular}{l|c|c|c|c}
\hline $\begin{array}{l}\text { Categories in order of } \\
\text { perceived sustainability }\end{array}$ & $\begin{array}{c}\text { Real } \mathbf{C O}_{2} \mathbf{e q} \\
\text { (in kg)* }\end{array}$ & $\begin{array}{c}\text { Real carbon } \\
\text { footprint class }\end{array}$ & $\begin{array}{c}\text { Perceived } \\
\text { sustainability** }\end{array}$ & $\begin{array}{c}\text { Perceived } \\
\text { carbon footprint*** }\end{array}$ \\
\hline Vegetables & 2.12 & 2 & 2.32 & 1.68 \\
Starchy food & 1.79 & 2 & 2.03 & 1.97 \\
Fruit & 0.90 & 3 & 2.01 & 1.99 \\
Meat and Dairy & 11.14 & 1 & 1.99 & 2.01 \\
Fish and Eggs & 2.63 & 1 & 1.86 & 2.14 \\
Sweets & 1.55 & 2 & 1.74 & 2.26 \\
\hline Drinks & 1.16 & 3 & 1.65 & 2.35 \\
\hline
\end{tabular}

*Sustainable class $\left(<1.5 \mathrm{~kg} \mathrm{CO} 2 \mathrm{eq}\right.$, light grey); don't know / non-perceived (1.5-2.5 kg $\mathrm{CO}_{2 \mathrm{eq}}$, medium grey); unsustainable class $(2.5 \mathrm{~kg} \mathrm{CO} 2 \mathrm{eq}<$, dark grey)

** Sustainable (3); don't know (2); unsustainable (1)

*** High Carbon Footprint (3); don't know (2); Low Carbon Footprint (1)

Table 3: Relation between characteristics and perceived sustainability (Multilevel ordered probit)

\begin{tabular}{|c|c|c|c|c|}
\hline & Coefficient & S. E. & Coefficient & S. E. \\
\hline Vegetables & Baseline & & & \\
\hline Fruit & $-0.3529 * * *$ & 0.1039 & & \\
\hline Meat and Dairy & $-0.6909 * * *$ & 0.1097 & & \\
\hline Starchy food & $-0.3480 * * *$ & 0.0628 & & \\
\hline Drinks & $-0.7175 * * *$ & 0.0991 & & \\
\hline Sweets & $-0.6051 * * *$ & 0.0909 & & \\
\hline Fish and Eggs & $-0.5848 * * *$ & 0.0982 & & \\
\hline Minimally processed foods & Baseline & & & \\
\hline Processed food ingredients & $-0.2340 * * *$ & 0.0703 & & \\
\hline Highly processed foods & -0.0045 & 0.0703 & & \\
\hline Non-UK & Baseline & & & \\
\hline $\mathbf{U K}$ & $0.5148 * * *$ & 0.1188 & & \\
\hline True carbon footprint $\left(\mathrm{kgCO}_{2}\right)$ & & & $0.0193^{* *}$ & 0.0082 \\
\hline$\mu_{1}$ & -0.5264 & 0.0653 & -0.1799 & 0.0599 \\
\hline$\mu_{2}$ & -0.1190 & 0.0736 & 0.2195 & 0.0475 \\
\hline Variance of the intercept & 0.0817 & 0.0221 & 0.0752 & 0.0216 \\
\hline var(kgco2_footprintperkgorlitre) & & & 0.0012 & 0.0005 \\
\hline Respondents & 42 & & 42 & \\
\hline Products & 70 & & 67 & \\
\hline Total & 2940 & & 2814 & \\
\hline Wald chi $^{2}(9)$ & $121.02 * * *$ & & & \\
\hline Wald $\operatorname{chi}^{2}(1)$ & & & $5.54 * *$ & \\
\hline Log pseudolikelihood & -2818.29 & & -2782.80 & \\
\hline
\end{tabular}

Significance is as follows: $* * *=0.1 ; * * *=0.05 ; * * *=0.01$. 
Table 4: Relation between characteristics and carbon footprint of each option (OLS)

\begin{tabular}{|c|c|c|}
\hline & Coefficient & S. E. \\
\hline Intercept & 0.1903 & 0.3270 \\
\hline Vegetables & Baseline & \\
\hline Fruit & $-0.7119 *$ & 0.4235 \\
\hline Meat \& dairy & $1.5932 * * *$ & 0.5555 \\
\hline Starchy food & 0.1365 & 0.4622 \\
\hline Drinks & $-0.8475 *$ & 0.4325 \\
\hline Sweets & -0.2883 & 0.4989 \\
\hline Fish \& eggs & 0.6481 & 0.3945 \\
\hline Minimally processed food & Baseline & \\
\hline Processed food ingredients & $0.8254 * *$ & 0.3438 \\
\hline Highly processed food & 0.0402 & 0.3158 \\
\hline Non-UK & Baseline & \\
\hline UK & 0.0102 & 0.3989 \\
\hline Observations & 67 & \\
\hline $\mathbf{F}(9,57)$ & $5.23 * * *$ & \\
\hline R-squared & 0.458 & \\
\hline Root MSE & 0.9166 & \\
\hline
\end{tabular}

Note: the dependent variable appears in logarithmic form. S.E. refers to robust standard errors. Significance is as follows: $* * *=0.1 ; * * *=0.05 ; * * *=0.01$ 


\section{FIGURES}

Figure 1: Comparison of real and perceived sustainability

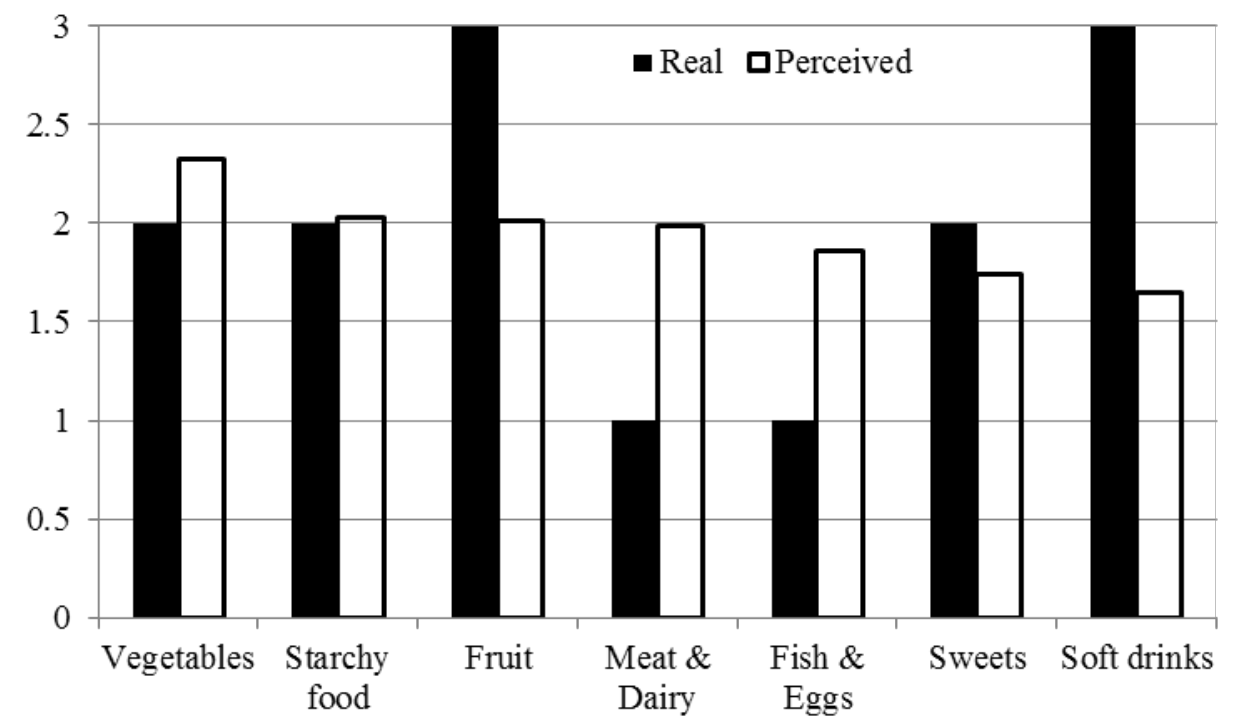

Figure 2: Relation between perceived and actual carbon footprint

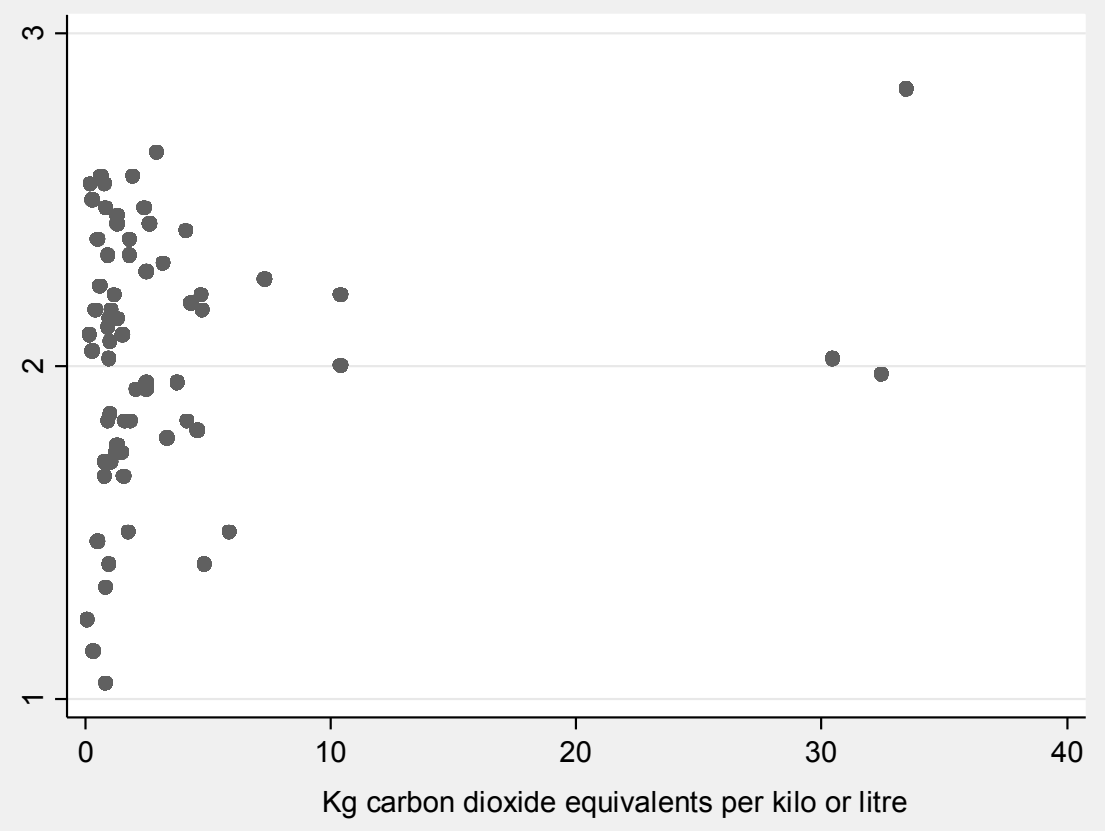


Figure 3: Marginal probability of classifying a product with a given characteristic as 'Sustainable'

a) Product category

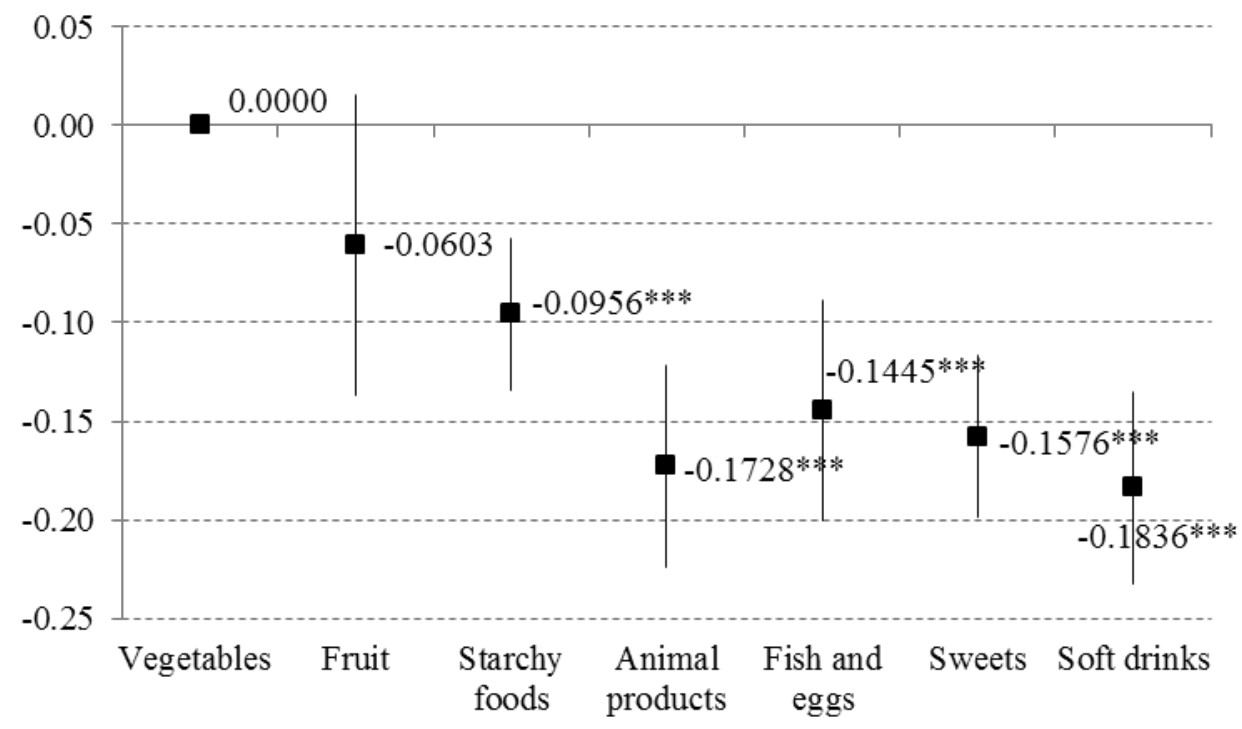

b) Level of processing

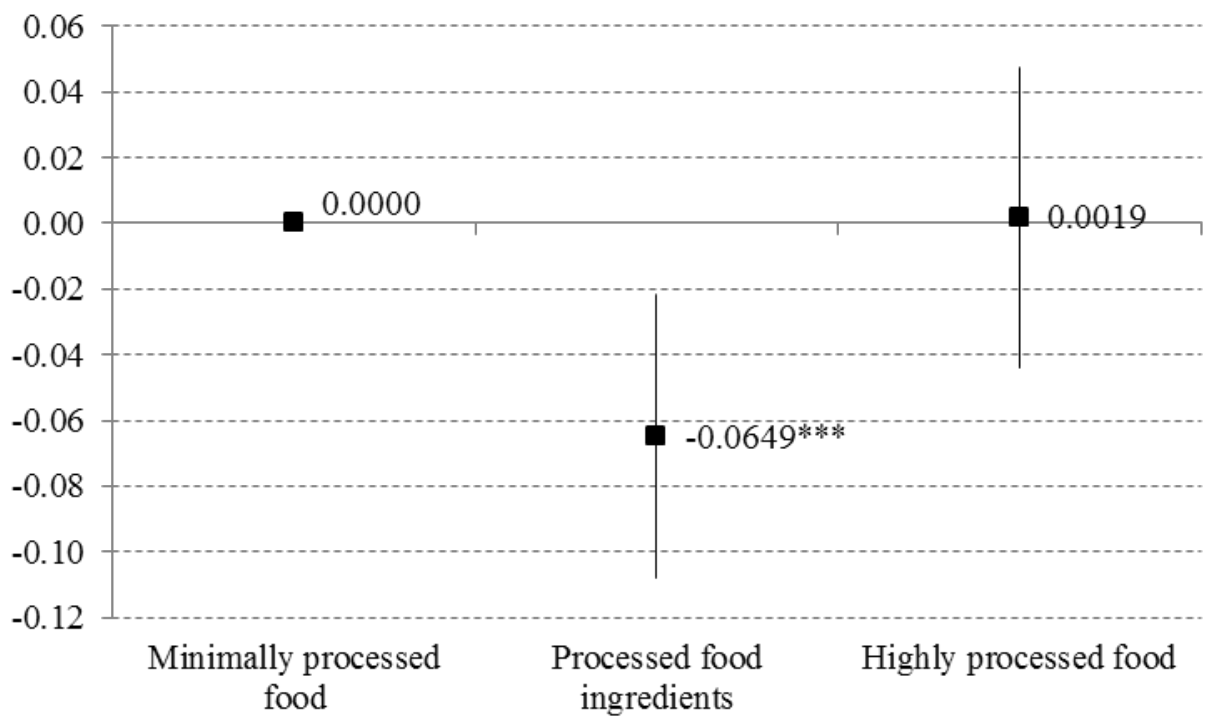


c) Origin

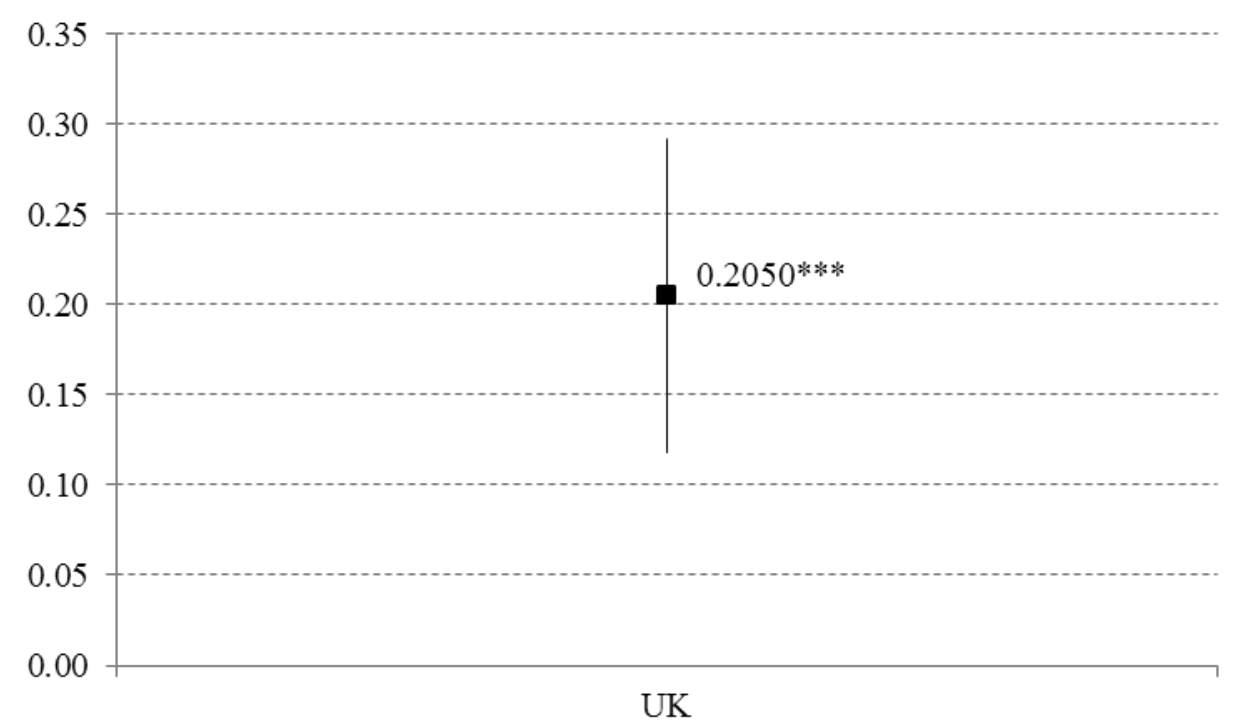

d) Carbon footprint

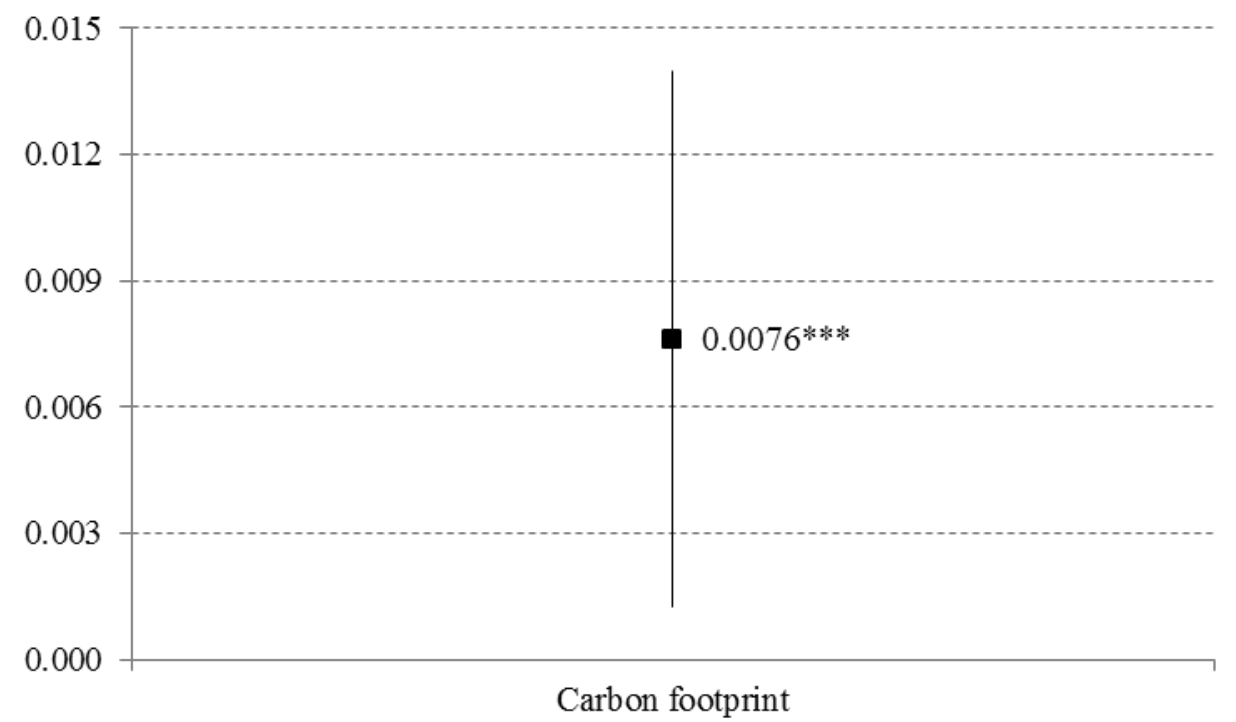

Note: Intervals are based on bootstrapped standard errors (1000 replications). Significance is as follows: $* * *=$ 0.01 . 
Figure 4: Distribution of marginal effects of carbon footprint in the sample

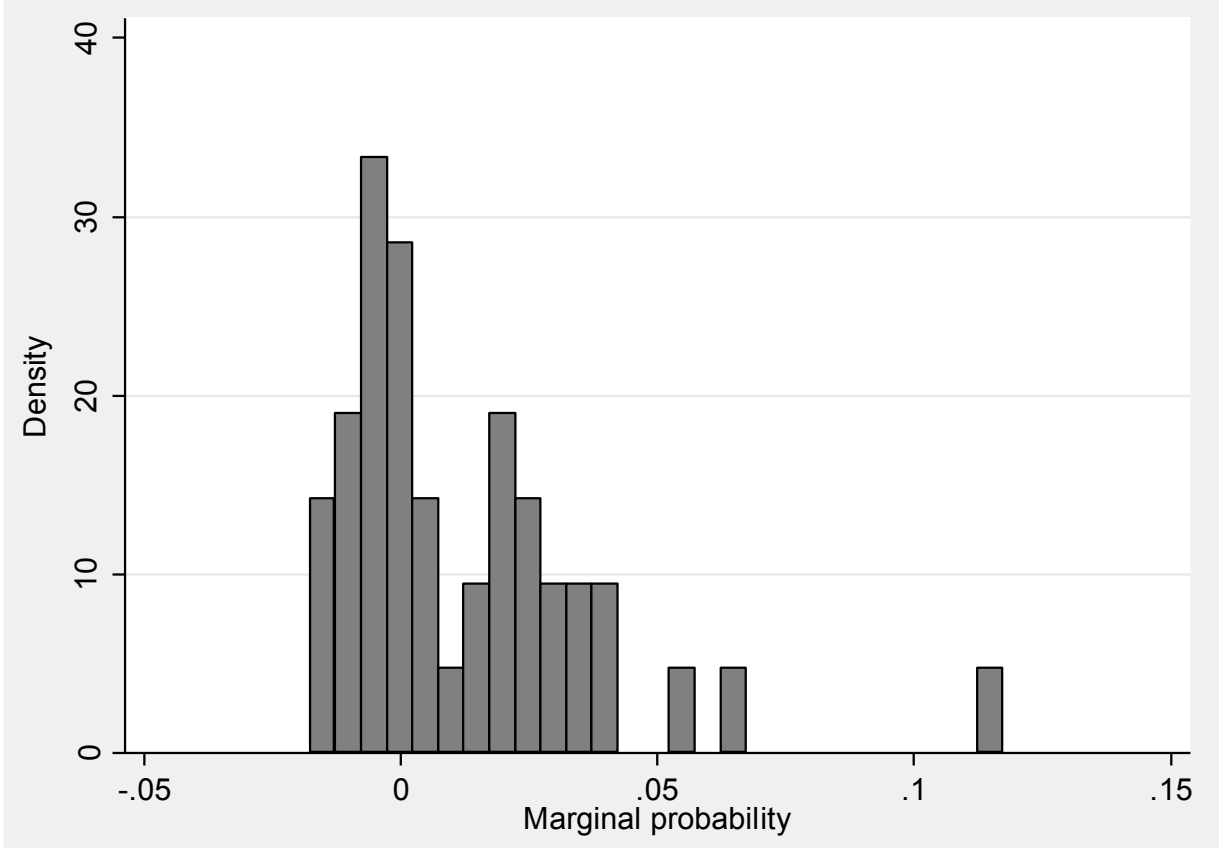


Figure 5: Food chain reputation: the market, owners, borrowers, and the technological $\mathrm{CO}_{2}$ dimension

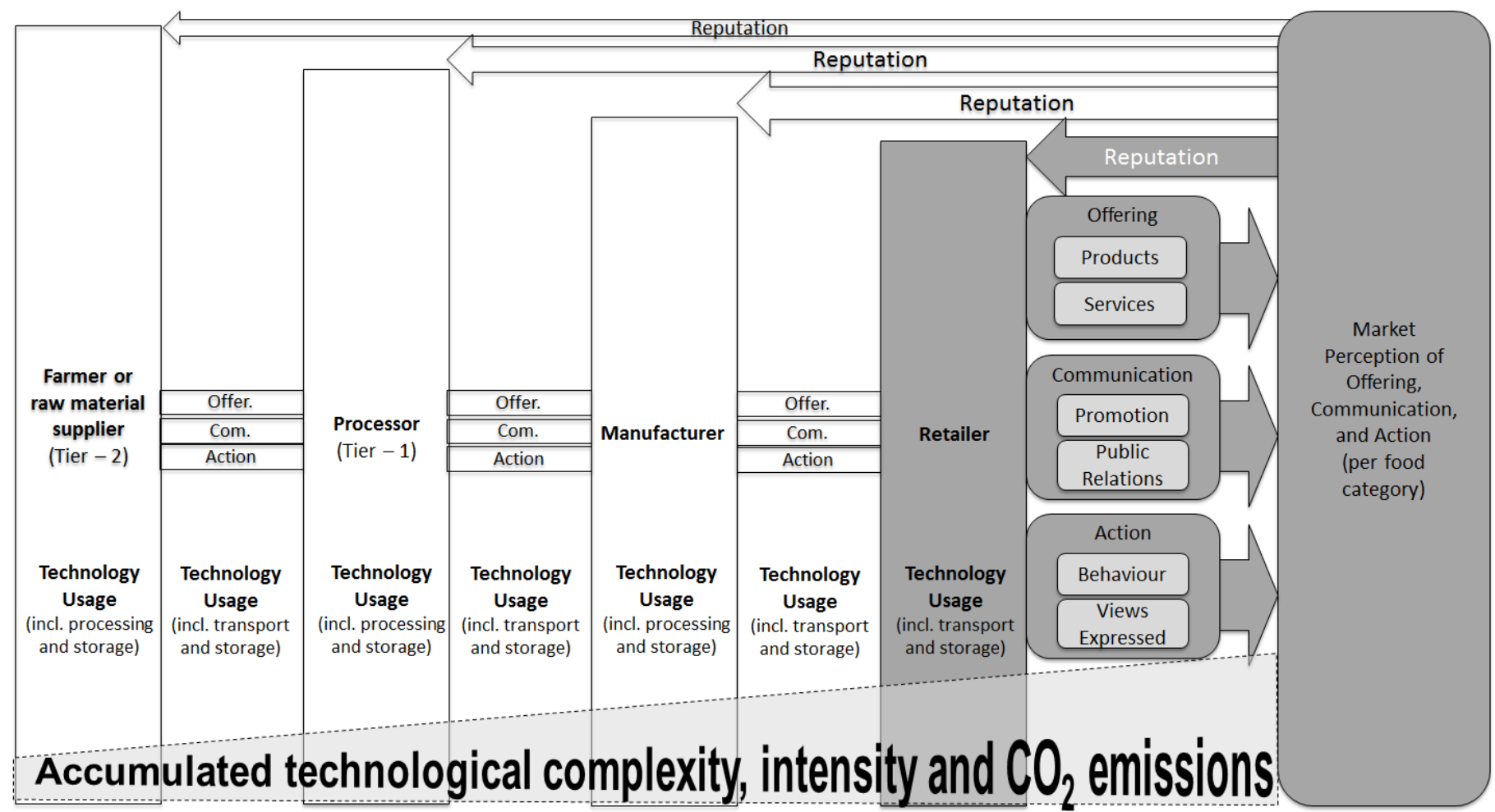

\begin{tabular}{|r|r|c|c|c|c|}
\hline \multicolumn{1}{|c|}{ Food Category } & \multicolumn{1}{c}{ Reputational Dimension } & $\begin{array}{c}\text { Farmer/ raw material } \\
\text { supplier (2nd Tier) }\end{array}$ & $\begin{array}{c}\text { Processor } \\
\text { (15t Tier) }\end{array}$ & Manufacturer & Retailer \\
\hline Industrial Products & Product Class Image & RB & RB & RO & RO \\
\hline Industrial Products & Image of Country of Origin & RO & RB & RO & RB \\
\hline Raw Ingredients & Product Class Image & RO & - & - & RO \\
\hline Raw Ingredients & Image of Country of Origin & RO & - & - & RB \\
\hline
\end{tabular}

Image of Country of Origin

$\mathrm{RB}=$ Reputational Borrowe

$\mathrm{RO}=$ Reputational Owner

Com. = Communication, consisting of promotion and public relations (including certifications, validations, etc.)

Offer. = Offering, consisting of products and services

Source: Based on Lemke and Petersen (2013). 


\section{APPENDIX: Carbon footprint of the products in the sample}

\begin{tabular}{|c|c|c|c|}
\hline Product name & $\mathrm{Kg} \mathrm{CO}_{2}$ per kg or litre & Product name & $\mathrm{Kg} \mathrm{CO}_{2}$ per kg or litre \\
\hline Alaskan Salmon & 2.90 & Mild cheddar & 10.40 \\
\hline Apples & 0.08 & Mozzarella & 7.30 \\
\hline Asparagus & 2.39 & Mr Kipling cakes & 0.91 \\
\hline Beans & 1.50 & Mushrooms & 0.48 \\
\hline Ben \& Jerry's ice cream & 0.64 & Nescafe & 1.30 \\
\hline Blueberries & 0.79 & NZ Lamb & 33.48 \\
\hline British beef steak & 30.48 & Olive Oil & 4.73 \\
\hline Caged eggs & 2.50 & One water & 0.18 \\
\hline Carrots & 0.83 & Organic eggs & 4.88 \\
\hline Cashews & 1.06 & Organic beef mince meat & 32.48 \\
\hline Chicken breast fillets & 4.18 & Organic blueberries & 0.79 \\
\hline Chopped tomatoes & 1.20 & Organic chicken & 4.58 \\
\hline Coca cola & 0.27 & Parsnips & 0.83 \\
\hline Cocoa & 4.30 & Pasta & 3.20 \\
\hline Cod fillets & 1.96 & Peas & 1.25 \\
\hline Cottage pie & 10.4 & PG tips tea & 4.10 \\
\hline Covent Garden Soup & NA & Pineapple & 1.30 \\
\hline Crispy salad & 3.30 & Pitta & 0.78 \\
\hline Dorset cereal & 1.00 & Pizza & 4.80 \\
\hline Evian & 0.21 & Quaker oats & 1.75 \\
\hline Fair-trade bananas & 0.51 & Raisins & 0.84 \\
\hline Fair-trade coffee & 1.30 & Soya & 0.28 \\
\hline Fair-trade oranges & 0.96 & Strawberries & 0.99 \\
\hline Frozen raspberries & 1.84 & Sugar & 0.38 \\
\hline Green \& black's chocolate & 1.80 & Tofu & 2.07 \\
\hline Honey & 1.00 & Tomatoes & 5.90 \\
\hline Hovis white bread & 1.56 & Tropicana orange juice & 0.95 \\
\hline Innocent smoothy & 0.96 & Tuna (canned) & 2.60 \\
\hline Kingsmill wholemeal bread & 1.45 & Turkey breast slice & 3.76 \\
\hline Kitkat & 1.80 & Turkey drummers & 3.76 \\
\hline Lemons & NA & Tyrrells & 2.50 \\
\hline Lettuce & 0.33 & Waitrose milk & 1.61 \\
\hline Mackerel (smoked) & 0.93 & Walkers & 2.50 \\
\hline Mango & NA & Yeo valley milk & 1.30 \\
\hline McCain potato chips & 0.57 & Yeo valley yoghurt & 1.06 \\
\hline
\end{tabular}

Source: Ccalc, available at http://www.ccalc.org.uk/ 